\title{
Afterload quantitation for evaluation of myocardial strain
}

\author{
Nathaniel Reichek ${ }^{2,4^{*}}$, Danielle Janosevic ${ }^{1,2}$, Meghana Jayam $^{1,2}$, Tazim Merchant ${ }^{1,2}$, Madhavi Kadiyala ${ }^{1,3}$, \\ Simcha Pollack², Jie J Cao ${ }^{1,3}$ \\ From 17th Annual SCMR Scientific Sessions \\ New Orleans, LA, USA. 16-19 January 2014
}

\section{Background}

Systolic myocardial strain is load dependent, but the CMR literature largely disregards effects of myocardial afterload on strain and strain rate. This may reflect well known limitations of conventional myocardial afterload assessment using wall stress analyses, which are based on erroneous assumptions about left ventricular(LV) geometry and/or myocardial material properties. Therefore, we compared the utility of a nongeometric afterload index (NGI) derived from LV pressure(P) volume $(\mathrm{V})$ and mass, which requires no assumptions about material properties, to that of conventional noninvasive end-systolic circumferential stress(CWS) as determinants of CMR LV circumferential strain(CST), ejection fraction(EF) and strain rate(SR) in normals(NL) and patients with nonischemic dilated cardiomyopathy $(\mathrm{CM})$.

\section{Methods}

We obtained breath-hold volumetric short-axis SSFP cines, cuff systolic P, systolic duration, LVV, M and EF, feature-tracking global CST(TomTec Imaging Systems) and mean SR in NLs( $\mathrm{n}=39,46 \%$ female, age 54.6(sd14.6) yrs) and $\mathrm{CM}(\mathrm{n}=35,23 \%$ female, age 50.8(sd15.0) yrs, EF $27.2 \%$ (sd10.8\%). CWS was calculated using Mirsky's formula(Biophys. J.1969) while NGI was determined as endsystolic PV/M.

\section{Results}

EF, CST and CSR were markedly reduced in CM compared to NL(EF $27.2 \%(\operatorname{sd} 10.8)$ vs $58.4 \%(4.6),(-53 \%)$ $\mathrm{p}<0.0001 ;$ CST $-10.7 \%(5.3)$ vs $-23.9 \%(4.3),(-55 \%)$, $\mathrm{p}<0.0001)$; $(\mathrm{CSR}-32.1 \% / \mathrm{s}(14.8)$ vs $-65.7(14.9) \mathrm{p}<0.0001)$. But CWS was also markedly elevated in CM versus NL
(CWS 307.6(9.2) vs 176.2(42.1)x 103 dyn/cm2,(+75\%), $\mathrm{p}<$ 0.0001). Thus afterload excess due to adverse LV remodeling, may account for most EF, strain and strain rate reduction in CM. However, PV/M was more markedly increased than CWS, (162.6(sd48.9) vs 84.4(18.4)(+93\%) $\mathrm{p}<0.0001)$ and correlated more closely and significantly with EF, CST and CSR than CWS in the expected inverse relationship in both NL and CM subgroups(Table 1). In stepwise regressions only $\mathrm{PV} / \mathrm{M}$ was a significant correlate of EF, strain and strain rate in both subgroups.

\section{Conclusions}

Afterload excess due to adverse LV remodeling is an important determinant of reduced myocardial and LV chamber function in $\mathrm{CM}$, making a major contribution

Table 1 Afterload Indices Versus EF, Strain and Strain Rate

\begin{tabular}{cccc}
\hline & $\mathbf{n}$ & Spearman $\mathbf{r}$ & $\mathbf{p}$ \\
\hline CWS vs EF NL & 39 & -0.29 & $\mathrm{~ns}$ \\
\hline PV/M vs EF NL & 39 & -0.59 & $<0.0001$ \\
\hline CWS vs EF CM & 35 & -0.40 & $<0.02$ \\
\hline PV/M vs EF CM & 35 & -0.63 & $<0.0001$ \\
\hline CWS vs CST NL & 39 & -0.28 & $\mathrm{~ns}$ \\
\hline PV/M vs CST NL & 39 & -0.46 & $<0.003$ \\
\hline CWS vs CST CM & 35 & -0.18 & $\mathrm{~ns}$ \\
\hline PV/M vs CST CM & 35 & -0.49 & $<0.003$ \\
\hline CWS vS SR NL & 39 & -0.28 & $\mathrm{~ns}$ \\
\hline PV/M vs SR NL & 39 & -0.40 & 0.012 \\
\hline CWS vS SR CM & 35 & -0.19 & $\mathrm{~ns}$ \\
\hline PV/M vs SR CM & 35 & -0.51 & $<0.002$ \\
\hline
\end{tabular}


to reductions in $\mathrm{EF}, \mathrm{CST}$ and $\mathrm{SR}$, but $\mathrm{PV} / \mathrm{M}$, a simple, nongeometric afterload index, is superior to conventional wall stress calculation as a quantitative afterload index.

\section{Funding}

\section{St. Francis Research Foundation.}

\section{Authors' details}

${ }^{1}$ Cardiac Imaging Program, St. Francis Hospital-the Heart Center, Roslyn, New York, USA. ${ }^{2}$ Research Department, St. Francis Hospital-the Heart Center, Roslyn, New York, USA. ${ }^{3}$ Internal Medicine, Stony Brook University, Stony Brook, New York, USA. ${ }^{4}$ Biomedical Engineering, Stony Brook University,

Stony Brook, New York, USA.

Published: 16 January 2014

doi:10.1186/1532-429X-16-S1-P320

Cite this article as: Reichek et al:: Afterload quantitation for evaluation of myocardial strain. Journal of Cardiovascular Magnetic Resonance 2014 16(Suppl 1):P320

Submit your next manuscript to BioMed Central and take full advantage of:

- Convenient online submission

- Thorough peer review

- No space constraints or color figure charges

- Immediate publication on acceptance

- Inclusion in PubMed, CAS, Scopus and Google Scholar

- Research which is freely available for redistribution

Submit your manuscript at www.biomedcentral.com/submit 